\title{
Empyema after internal jugular catheterisation in rheumatoid arthritis
}

\author{
VB ANTONY, SA SAHN \\ From the Pleural Space Laboratory, Webb-Waring Lung Institute, Division of Pulmonary Sciences, Department of \\ Medicine, University of Colorado Health Sciences Center, Denver, Colorado, USA
}

\begin{abstract}
Violation of the pleural space is a known complication of percutaneous central venous catheterisation. Pneumothorax, hydrothorax, and haemothorax ${ }^{1}$ have been reported after internal jugular vein catheterisation. We were asked to see a patient with rheumatoid arthritis who developed an insidious staphylocoscal empyema as a complication of jugular venous catheterisation.
\end{abstract}

\section{Case report}

A 67-year-old white man with rheumatoid arthritis was admitted to hospital for aortic valve replacement and coronary artery bypass. Medications included indomethacin, digoxin, and frusemide. A right internal jugular catheter was inserted on the day of operation and removed on the fourth postoperative day without apparent complications. The patient's postoperative course was

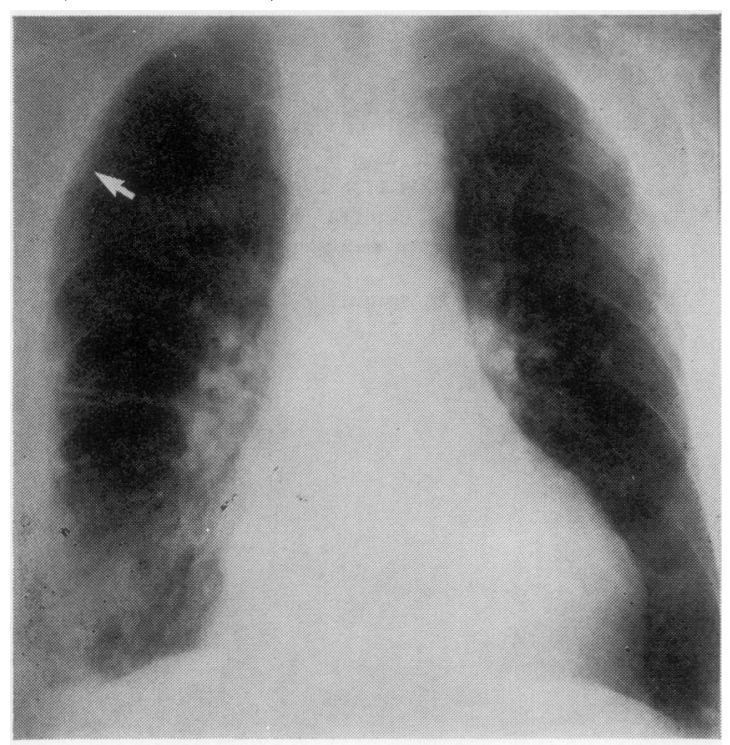

(a)

Address for reprint requests: Dr SA Sahn, Division of Pulmonary Sciences, Box C-272, University of Colorado Health Sciences Center, 4200 East Ninth Avenuc, Denver, Colorado 80262, USA.

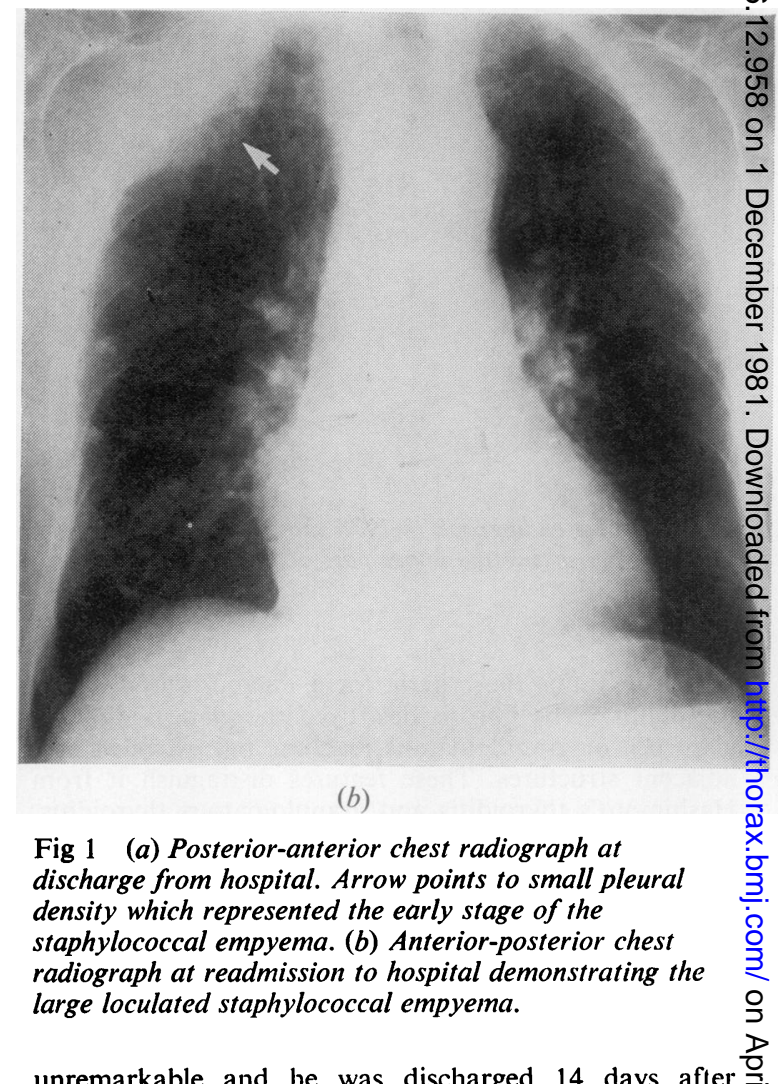

unremarkable and he was discharged 14 days after operation. A chest radiograph two days before discharge $\bar{N}$ is shown in fig 1a. Five days later, he returned with $\sigma$ complaints of weakness and lethargy. Physical examin- $\mathrm{N}$ ation on admission showed an ill-looking man with a N blood pressure of $92 / 60 \mathrm{mmHg}$, a pulse rate of 100 per $\sigma$ minute, a temperature of $36 \cdot 2^{\circ} \mathrm{C}$, and respiratory rate of 24 per minute. His jugular venous pressure was $12 \mathrm{~cm}$ at $45^{\circ}$. Examination of the chest showed dullness to per- $\mathbb{Q}$ cussion in the right infraclavicular and axillary arcas and distant breath sounds. A grade $2 / 6$ systolic ejection murmur was heard at the left sternal border. First and second heart sounds were normal and there was an 
audible valve click. The liver was palpable $3 \mathrm{~cm}$ below the costal margin and the spleen was not palpable. He had stigmata of rheumatoid arthritis. Laboratory data showed a leucocyte count of $11.2 \times 10^{9} / 1$ with a shift to the left. A chest radiograph (fig 1b) showed a large loculated pleural density which was shown by ultrasound to be fluid. A thoracentesis under ultrasound guidance revealed purulent fluid with a leucocyte count of $329.7 \times$ $10^{9} / 181 \%$ of which were polymorphonuclear cells. A gram stain of the pleural fluid showed a large number of Gram positive cocci in clusters. After digital exploration, a chest tube was inserted and a course of intravenous oxacillin begun. However, the patient's condition continued to deteriorate, and he required intubation and mechanical ventilation. Subsequently, blood cultures grew Staphylococcus aureus. The patient developed septic shock, disseminated intravascular coagulation, and had a cardiorespiratory arrest 48 hours after admission from which he could not be resuscitated. A necropsy was not performed.

\section{Discussion}

The internal jugular venous approach to central venous catheterisation is thought by some to be safer than subclavian catheterisation. However, it is fraught with the same risks as the subclavian approach and serious pleural space complications can occur in inexperienced hands or when the physician is not attentive to detail. ${ }^{2}$

This case illustrates two points. First, empyema, a previously unreported complication, can oscur after internal jugular venous puncture without concomitant pneumothorax or haemothorax. Second, patients with rheumatoid arthritis tend to have a greater susceptibility to infections, particularly staphylococcal, ${ }^{3}$ and an increased incidence of empyema; ${ }^{4}$ these patients are probably at increased risk of developing infectious complications from central venous catheter insertion. The insidious nature of the empyema (diagnosed seven days after the predischarge radiograph showed a pleural abnormality) could have been due in part to the "masking" effect of indomethacin. ${ }^{5}$

Presumably, at the time of jugular venous catheterisation, the needle tip entered the pleural space without causing a pneumothorax but introduced staphylococci from the skin which was not handled well by the host's defence mechanisms. It is important with the use of povidone iodine as a topical antiseptic agent that adequate time be allowed to elapse (two minutes) before needle insertion, as skin bacteria, including staphylococci, may require that amount of time for killing. ${ }^{6}$ Meticulous aseptic technique should be followed in all patients requiring central venous catheterisation but especially in patients, such as those with rheumatoid disease, prone to infectious complications.

This work was supported by Training Grant No T32 HL 07085 from the National Heart, Lung and Blood Institute.

\section{References}

${ }^{1}$ McGoon MD, Bernedetto PW, Greene BM. Complications of percutaneous central venous catheterization: a report of two cases and review of the literature. John Hopkins Med J 1979;145:1-6.

2 Bernard RW, Stahl WM. Subclavian vein catheterization: a prospective study. Ann Surg 1971;101:534-6.

${ }^{3}$ Kellgren JH, Ball J, Farbrother RW, Barnes KL. Suppurative arthritis complicating rheumatoid arthritis. $\mathrm{Br}$ Med J 1958;1:1193-200.

4 Jones FL, Blodgett RC. Empyema in rheumatoid pleuropulmonary disease. Ann Intern Med 1971;74: 665-71.

s Sahn SA, Lakshminarayan S, Char DC. "Silent" empyema in patients receiving corticosteroids. Am Rev Respir Dis 1973;107:873-6.

6 Vander Wyk RW. The in vitro microbicidal activity of betadine surgical scrub on hospital isolated organisms. In: Medical and surgical antisepsis with betadine microbicides. New York: Purdue Frederick Company, 1972: $17-22$. 